\title{
An Investigation of the Reasons for Failure in Patients with A Fixed Prosthesis
}

\author{
Tuğçe Kavaz ${ }^{1 *}$, Kadir Gördeli ${ }^{2}$ and Nuran Yanıkoğlü ${ }^{1}$ \\ ${ }^{1}$ Atatürk University Faculty of Dentistry-Department of Prosthodontics, Turkey \\ ${ }^{2}$ Eskişehir Oral and Dental Health Hospital, Turkey
}

*Corresponding author: Tuğçe Kavaz, Atatürk University Faculty of DentistryDepartment of Prosthodontics Yakutiye/ Erzurum, Turkey.

Received Date: December 21, 2020

Published Date: January 19, 2021

\begin{abstract}
Complications seen in tooth-supported fixed prosthetic restorations are mentioned in many places in the literature. In order to make more successful prostheses, it is important to establish a relationship between patients' complaints and clinical and radiological findings. The study was conducted with 90 patients between 2019-2020. The aim of this study was to compare the failure rates of the fixed prosthesis used by the patients according to the dental supported fixed prosthetic failure scale in terms of age, gender, clinical and radiological status, education level, duration of use, and prosthesis material.
\end{abstract}

Methods: Failure classification in prosthetic restorations was made with Manappallil's failure level scale seen in tooth-supported fixed prostheses. The SPSS v20 program was used to analyze the data. Categorical variables were presented as numbers and percentages while numerical variables were presented as mean and standard deviation. Relationships between numerical variables, student T test, Kruskal Wallis and Spearman correlation tests, and relationships between categorical variables were determined by a chi-square test. p $<0.05$ was considered statistically significant.

Results: While there was a significant relationship between failure class and prosthesis type (crown or bridge), there was no relation between $(\mathrm{p}<0.05)$ mean age, prosthesis type, and prosthetic material. There was a moderate positive correlation between age and failure classes $(\mathrm{p}<0.001$, $r=0.39$ ). It was observed that there was a significant relationship between duration of prosthesis use and failure classes $(\mathrm{p}<0.05)$. There was a low degree of positive correlation between age and duration of use $(p<0.05, r=0.23)$. There was no relationship between the clinical condition and radiological findings of the patient and the education level and failure classification.

Keywords: Tooth supported fixed dental prosthesis; Complication; Failure classification; Prognosis

\section{Introduction}

When tooth-supported fixed prostheses fail, the question the clinician has is whether the problem can be easily solved or whether many complex treatments will be needed to achieve the hopedfor result [1]. Nowadays, fixed prostheses are the first choice of patients in the form of tooth or implant-supported because of their psychological and social advantages as well as their ease of use. Although chairside dentistry has become widespread with rapid production, and complications have decreased with advances in materials science, over time, some restorations have to be removed for aesthetic (cracks, fractures, wear, discoloration), biological (caries, devitalization of abutment teeth, periodontal problems), of mechanical reasons (loss of retention, broken of abutment teeth) [2]. There are many reasons for removing tooth-supported fixed dentures. A priority is the loss of retention from endodontic causes and caries. Endodontic chronic or acute inflammations, periodontal pathology, or caries in the abutment teeth are biological complications of fixed prostheses while connection weaknesses in the infrastructure, continuous de-cementation and chipping are considered mechanical complications [3]. Other complications include marginal mismatches, insufficient or excessive contours, 
and insufficient aesthetic parameters [4]. While the most common primary complication is loss of prosthesis retention, caries in the abutment is the most common late complication $[5,6]$.

The material to be used should meet the aesthetics requirements of the patient as well as functional and phonation needs. The tissue compatibility of the restorations should be good, non-toxic, not variable with mouth temperature, durable, not subject to discoloration, and not cause periodontal problems [7, 8]. It is not possible to determine a material whose long-term success was investigated as a result of a short-term in vitro study. In addition, results from in vitro studies do not always support clinical results. Therefore, in vitro studies should be supported by in vivo studies [9]. The aim of this study was to classify the complications of patients who have applied for help due to their complaints regarding toothsupported fixed prostheses according to their failure level and to compare the tooth-supported fixed prostheses used by patients according to their age, gender, education level, prosthesis use time, prosthesis material, and clinical and radiological status.

\section{Materials and Methods}

The study was carried out with the approval of the Atatürk University Faculty of Dentistry Ethics Committee (\#06-2/6), and written and verbal informed consent was obtained from the respondents before the examination. The sample study was conducted randomly among patients who had fixed prosthetic restorations performed in different clinics in Eskișehir Oral and Dental Health Hospital. First, demographic characteristics of the patient such as profession, age, and gender were transferred to the forms. After an intraoral examination, the dental history, the type of prosthesis used by the patients (crown or bridge), the prosthesis material, and the length of time the prosthesis was used by the patient were ascertained. The failure classification of the prosthetic restorations was made using Manappallil's [1] failure level scale (Table 1) as seen in tooth-supported fixed prostheses and was accepted as an independent variable. The relationships between variables were analyzed with cross tables, the Pearson chi-square test, Spearman's correlation, an independent t test, and a Kruskal Wallis test.

The Statistical Package for the Social Sciences (SPSS v20) program was used for the analysis of the data. Categorical variables were presented as number and percentage while numerical

Table 1: Failure Classification by Manapallil's Level of Failure [1].

\begin{tabular}{|c|c|}
\hline Class & Description \\
\hline Class 1 & Failure can be resolved without replacing the prosthetic restoration. \\
\hline Class 2 & $\begin{array}{r}\text { Failure can be resolved without replacing the prosthetic restoration; however, repair or restoration of the abutment tooth structure is } \\
\text { needed. }\end{array}$ \\
\hline Class 3 & Failure can only be solved by replacing the prosthetic restoration; there is no need for repair or restoration of the abutment tooth structure. \\
\hline Class 4 & Failure can only be resolved by replacing the prosthetic restoration; the abutment tooth structure needs repair or restoration. \\
\hline Class 5 & Failure cannot be solved by simply replacing the prosthetic restoration; however, fixed prosthetic treatment can be performed by adding \\
\hline Class 6 & Failure cannot be achieved by changing the prosthetic restoration, adding an abutment or planning a new prosthesis, and fixed prosthetic \\
treatment is not possible.
\end{tabular}

variables were presented as mean and standard deviation. Compliance of numerical variables to normal distribution was investigated by the Kolmorov Smirnov test, the $\mathrm{z}$ values calculated for skewness and kurtosis, and by graphing methods. The student $\mathrm{T}$ test was used for binary group comparisons of normally distributed numerical variables, the Kruskal Wallis for comparisons of nonnormally distributed numerical variables between more than two groups, and Chi-Square tests were used for the comparison of categorical variables. Spearman's rho correlation analyzes were used to investigate the relationships between continuous variables.

\section{Results}

The study was conducted with one person between the ages of 18-30, 33 people between the ages of $30-50$, and 56 people between the ages of 50-85. Fixed prosthetic restorations of a total of 90 patients between the ages of $18-85$ were evaluated. The educational status and professions of the participants are as follows: 40 people (44\%) had a primary school education, eight people (9\%) middle school, 20 people (22\%) high school, 15 people (17\%) university, six people (6\%) master's or doctorate degree; and one person (1\%) was illiterate. 26 people (29\%) were housewives, 26 (29\%) were retired, 10 (11\%) were workers, 17 (19\%) were civil servants, and $11(12 \%)$ were self-employed. There was no relationship between education level and failure class. According to failure classification, $10 \%$ of patients were Class 1, $10 \%$ in Class 2, 23.3\% in Class 3, $20 \%$ in Class 4, 14.4\% in Class 5, and $22.2 \%$ in Class 6 (Table 2).

Gender distributions according to failure classes are shown in (Table 3). $48 \%$ of the participants in the study were male and $52 \%$ were female.

$82.2 \%$ of the patients participating in the study had metal porcelain $(n=74)$, and $17.8 \%(n=16)$ had metal acrylic restorations. There was no significant relationship between genders and material type (Table 4) and failure classes ( $p>0.05)$ (Classes 1-2 were combined during analysis).

It was observed that $26 \%$ of the prostheses of the patients participating in the study were made of a full crown, $60 \%$ an aesthetic bridge, $10 \%$ a hygienic bridge, $3 \%$ a telescope bridge, and $1 \%$ a laminate crown. There was a significant relationship between failure classification and the type of prosthesis (crown or bridge) $(p<0.05)$. Complete crowns were to be less successful. Membership numbers were not included in the study (Table 5). 
Table 2: Patient Distributions According to Failure Classes.

\begin{tabular}{|c|c|c|}
\hline & Percent & Number \\
\hline Class 1 & $10 \%$ & 9 \\
\hline Class 2 & $10 \%$ & 21 \\
\hline Class 3 & $23.30 \%$ & 18 \\
\hline Class 4 & $20 \%$ & 13 \\
\hline Class 5 & $14.40 \%$ & 20 \\
\hline Class 6 & $2.20 \%$ & \\
\hline
\end{tabular}

Table 3: Failure Classes Distribution by Gender.

\begin{tabular}{|c|c|c|c|c|c|c|}
\hline & Class 1 & Class 2 & Class 3 & Class 4 & Class 5 & Class 6 \\
\hline Female & $67 \%$ & $44 \%$ & $48 \%$ & $44 \%$ & $46 \%$ & $60 \%$ \\
\hline Male & $33 \%$ & $56 \%$ & $52 \%$ & $56 \%$ & $54 \%$ & $40 \%$ \\
\hline
\end{tabular}

Table 4: Failure Class Distribution According to Prosthetic Construction Materials.

\begin{tabular}{|l|c|c|}
\hline & Metal-Porcelain $\mathbf{\% 2} \% \mathbf{n = 7 4}$ & Metal- Acrylic $\mathbf{1 8 \%} \mathbf{n = 1 6}$ \\
\hline Class 1 & $9 \% \mathrm{n}=8$ & $11 \% \mathrm{n}=1$ \\
\hline Class 2 & $78 \% \mathrm{n}=7$ & $2 \% \mathrm{n}=2$ \\
\hline Class 3 & $81 \% \mathrm{n}=17$ & $19 \% \mathrm{n}=4$ \\
\hline Class 4 & $83 \% \mathrm{n}=15$ & $17 \% \mathrm{n}=1$ \\
\hline Class 5 & $92 \% \mathrm{n}=12$ & $8 \% \mathrm{n}=1$ \\
\hline Class 6 & $75 \% \mathrm{n}=15$ & $25 \% \mathrm{n}=5$ \\
\hline
\end{tabular}

Table 5: Relationship Between Prosthesis Type and Failure Class.

\begin{tabular}{|c|c|c|}
\hline & Bridge 30\% $\mathbf{N}=\mathbf{2 7}$ & Full Crown $\mathbf{7 0} \% \mathbf{N}=\mathbf{6 3}$ \\
\hline Class 1 & $67 \% \mathrm{n}=6$ & $33 \% \mathrm{n}=3$ \\
\hline Class 2 & $56 \% \mathrm{n}=5$ & $44 \% \mathrm{n}=4$ \\
\hline Class 3 & $19 \% \mathrm{n}=4$ & $81 \% \mathrm{n}=17$ \\
\hline Class 4 & $22 \% \mathrm{n}=4$ & $78 \% \mathrm{n}=14$ \\
\hline Class 5 & $15 \% \mathrm{n}=2$ & $85 \% \mathrm{n}=11$ \\
\hline Class 6 & $30 \% \mathrm{n}=6$ & $70 \% \mathrm{n}=14$ \\
\hline
\end{tabular}

Table 6: Relationship Between Duration of Use, Patient Age and Failure Class.

\begin{tabular}{|c|c|c|c|c|c|c|}
\hline & Class 1 & Class 2 & Class 3 & Class 4 & Class 5 & Class 6 \\
\hline Average Usage Time & 1,33 year & 6.67 year & 7.55 year & 10.22 year & 6.38 year & 8.75 year \\
\hline Average Age & $45 \pm 12$ age & $56 \pm 10$ age & $53 \pm 12$ age & $51 \pm 10$ age & $62 \pm 15$ age & $63 \pm 6$ age \\
\hline
\end{tabular}

The average age of women in the study group was $54.48 \pm 11$, and the average age of men was $56.57 \pm 13$. While there was no relationship between mean age, prosthesis type, and prosthetic material ( $p>0.05$ ), there was a moderate and significant positive correlation between age and failure classes $(p<0.001, r=0.39)$. In addition, there was a low level of positive correlation between age and duration of use ( $p<0.05 \mathrm{r}=0.23)$ (Table 5). Average usage time was 1.33 years in Class 1 (min-max: $0-4$ years), 6.67 years in Class 2 (min-max: 0-30 years), 7.55 years in Class 3 (min-max: 0-28 years), 10.22 years in Class 4 (min-max: 0-30 years), 6.38 years in Class 5 (min-max: 0-22 year), and 8.75 years in Class 6 (min-max: 1-23). There was a significant relationship between prosthesis use time and failure classes (Table 6). ( $\mathrm{p}<0.05$ ) (Class 4, 5, 6 combined)

\section{Clinical evaluation}

Looking at the clinical appearance of these restorations, $43(48 \%)$ of the prostheses had open crown edges, $47(\% 52)$ had gingival problems, $31(\% 34)$ had a color change in the crowns, $25(\% 28)$ had calculus formation, 21(\%23) had a broken prosthesis, and $12(\% 13)$ restorations had a normal clinical appearance.

\section{Radiological evaluation}

When the radiological examinations of the patients participating in the study were performed, enlargement of the periodontal spaces of the crowns in $34(\% 8)$ patients, secondary caries in $31(34 \%)$, lesions at the root apex $21(23 \%)$, resorption in the root 
region or bone in $16(18 \%)$ were detected. There was no significant correlation between clinical and radiological evaluations and failure classification $(\mathrm{p}>0.05)$.

\section{Discussion}

The aim of this study was to determine the failure level of dental-supported fixed prostheses that may be encountered in the clinic and to aid in the prediction of the prognosis of the cases, according to this level. The fixed prosthesis failure scale used in this study can be included in future studies as it is easily applicable, and there are few studies in the literature using a scale [10-12]. Although some authors recommend using many complication and failure classifications or scales, it has been seen that, in the past few years, no scales were preferred in the literature regarding complications in fixed prostheses, and the researchers continued these studies within their own knowledge. Standardization of failure scales for new and easily applicable tooth-reinforced fixed prostheses will undoubtedly facilitate the comparison of national and international data.

According to the results of this study, a small portion of the patients who applied to our clinic were included in Class 1 and Class 2, while most remained in other classes. The rate of Classes $3,4,5$ constituted $56.6 \%$ of the patients in total. Meşe, et al. [10] Shah, et al. [11] achieved similar results in a study in which they evaluated the failure of tooth-reinforced fixed prostheses. It is not surprising that similar results occur in developing societies because patients may apply to the clinic due to their socio-economic status, waiting for the problem to progress. Goodacre, et al. [2] examined the relationship between the number of members and the complications seen in fixed prostheses in depth in their review. The biggest limitation of our study may be the uncertainty of the number of units in the prosthesis of the patients.

In addition, some types of complications were statistically combined and analyzed while clinical and radiological evaluation was performed, but no correlation was found between the failure classes. Increasing the sample size and rearranging the forms according to the examination findings and failure scale and perhaps a new scale study may be beneficial for future researchers [13]. At the same time, the few review studies in the literature addressing the complications of tooth-supported fixed prostheses in recent years may be because the advantages of implant-supported fixed or removable prostheses have reduced researchers' desire to investigate the underlying causes of the failure of traditional toothsupported fixed prostheses. These reviews [14-17] compare the advantages and disadvantages of metal-supported and full-ceramic tooth-supported fixed restorations or implant-supported fixed prostheses in line with today's world. In addition, single-unit or multi-unit restorations may be more beneficial in terms of solving the long-term effects of complications by considering separately the complications that occur [14-17]. Parallel to the work of Meșe et al [10], the progression of failure and the duration of use of the prosthesis increased with age. In contrast to previous studies, it should be kept in mind that, although a full crown is more successful than bridges, the small sample size in our study might have changed the results. Also, contrary to this study, there was no relationship between prosthetic material and failure classification in our study.

\section{Conclusion}

The following points can be specified within the boundaries of the study; it was observed that patients applied to the prosthodontics clinic when the rate of complications increased, and the duration of using prostheses increased as the patients got older. New studies are needed to evaluate the number of units.

\section{Acknowledgement}

For his contribution, we would like to thank Dr. Ezel Bilge Yerli. No financial support was received for the work presented in the article, and the authors do not have any commercial or interest in relation to the work.

\section{Conflict of Interest}

No conflict of interest.

\section{References}

1. Manappallil JJ (2008) Classification system for conventional crown and fixed partial denture failures. J Prosthet Dent 99(4): 293-298.

2. Goodacre CJ, Bernal G, Rungcharassaeng K, Kan JY (2003) Clinical complications in fixed prosthodontics. J Prosthet Dent 90(1): 31-41.

3. Sermet B, Değer S, İssever H (1997) Investigation of the using time and reasons of removal of fixed prosthetic restorations. Gazi University Faculty of Dentistry Journal 14(1-2): 79-86.

4. Cheung GS, Lai SC, Ng RP (2005) Fate of vital pulps beneath a metalceramic crown or a bridge retainer. Int Endod J 38(8): 521-530.

5. Karlsson S (1986) A clinical evaluation of fixed bridges, 10 years following insertion. J Oral Rehabil 13(5): 423-432.

6. Valderhaug J (1991) A 15-year clinical evaluation of fixed prosthodontics. Acta Odontol Scand 49(1): 35-40.

7. Heintze SD, Rousson V (2010) Survival of zirconia- and metal-supported fixed dental prostheses: a systematic review. Int J Prosthodont 23(6): 493-502.

8. Mjör IA, Moorhead JE, Dahl JE (2000) Reasons for replacement of restorations in permanent teeth in general dental practice. Int Dent J 50(6): 361-366

9. Koçak Büyükdere A, Sertgöz A (2015) Evaluation of Fixed Prosthetic Restorations with In Vivo Studies. Atatürk University Faculty of Dentistry Journal 25 (1).

10. Meşe A, Kale E, Özcan M, Yıldız AD, Kaya E (2017) Evaluation of failures encountered in tooth-supported fixed dentures in the Southeastern Anatolia Region. Mersin Univ Journal of Health Science 10(3): 194-201.

11. Shah DS, Vaishnav K, Duseja S, Joshi R (2014) Clinical Evaluation of Fixed Dental Prosthesis Failures in Indian Population: An In Vivo Study. Advances in Human Biology 4(3): 37-43.

12. Riaz W, Aslam A, Aziz S (2018) Dental Prosthesis. The Professional Medical Journal 25(08): 1261-1264. 
13. (2015) Ramakrishnan HH Understanding Problems and Failures in TSFDP.

14. Sailer I, Makarov NA, Thoma DS, Zwahlen M, Pjetursson BE (2015) All-ceramic or metal-ceramic tooth-supported fixed dental prostheses (FDPs)? A systematic review of the survival and complication rates. Part I: Single crowns (SCs). Dent Mater 31(6): 603-623.

15. Pjetursson BE, Sailer I, Makarov NA, Zwahlen M, Thoma DS (2015) All-ceramic or metal-ceramic tooth-supported fixed dental prostheses (FDPs)? A systematic review of the survival and complication rates. Part II: Multiple-unit FDPs. Dent Mater 31(6): 624-639.
16. Pjetursson BE, Valente NA, Strasding M, et al. (2018) A systematic review of the survival and complication rates of zirconia-ceramic and metal-ceramic single crowns. Clin Oral Implants Res 29 Suppl 16: 199214.

17. Sailer I, Strasding M, Valente NA, et al. (2018) A systematic review of the survival and complication rates of zirconia-ceramic and metal-ceramic multiple-unit fixed dental prostheses. Clin Oral Implants Res 29 Suppl 16: 184-198. 